\title{
Perineurial Glia
}

\author{
Sarah Kucenas \\ Department of Biology, University of Virginia, Charlottesville, Virginia 22904 \\ Correspondence: sk4ub@virginia.edu
}

Although the ultrastructure of peripheral nerves has been known for nearly 200 years, the developmental origins and functional roles of all five main components of these specialized nervous system conduits are still poorly understood. One of these understudied nerve elements, the perineurium, is a component of the blood-nerve barrier and is essential for protecting axons and their associated Schwann cells from ionic flux, toxins, and infection. However, until recently, it was thought that this vital nerve tissue was derived from the mesoderm and simply served a structural/barrier function with no other influence on the development, maintenance, or regeneration of peripheral nerves. Recent work in zebrafish using in vivo time-lapse imaging, genetic manipulation, and laser axotomy is shedding light on the origin and roles of this previously ignored glial nerve component and is changing how we view development of the nervous system.

\begin{abstract}
All nerves of the peripheral nervous system A(PNS) are structurally identical, consisting of five main components (Fig. 1) (Gamble and Eames 1964; Cravioto 1965; Shantha and Bourne 1968; Akert et al. 1976; Nordlander et al. 1981). Central to all sensory and motor nerves are axons. Within dorsal and ventral nerve roots, only sensory or motor axons, respectively, reside within these conduits (Kuczynski 1980). However, once the individual nerve roots found in each spinal cord segment merge and become spinal nerves, these two populations of axons are bundled together into what is known as a mixed or spinal nerve. Surrounding the axons within these nerves are Schwann cells, which are the myelinating glial population of the PNS (for review, see Mirsky and Jessen 1999; Jessen and Mirsky 2005). Large caliber axons (typically larger than $1.0 \mu \mathrm{m}$ in diameter) are mye-
\end{abstract}

linated, whereas smaller diameter axons are often associated within nonmyelinating Schwann cells known as Remak bundles (Fig. 1). These axon-Schwann cell complexes reside within the endoneurium, a neural crest-derived tissue, which synthesizes and secrets extracellular matrix components that support the nerve (Fig. 1) (Shantha and Bourne 1968). Each mature peripheral nerve has multiple fascicles of these axon-Schwann cell complexes in endoneurium and they are individually ensheathed by the perineurium (Fig. 1) (Shanthaveerappa and Bourne 1962, 1963; Burkel 1967; Shantha and Bourne 1968; Akert et al. 1976). This nerve component is made up of multiple perineurial cells that are connected via tight junctions, making this structure a component of the blood-nerve barrier, protecting the interior of the nerve from toxins, infection, and ionic flux (Shanthaveer-

Editors: Ben A. Barres, Marc R. Freeman, and Beth Stevens

Additional Perspectives on Glia available at www.cshperspectives.org

Copyright (C) 2015 Cold Spring Harbor Laboratory Press; all rights reserved; doi: 10.1101/cshperspect.a020511

Cite this article as Cold Spring Harb Perspect Biol 2015;7:a020511 


\section{S. Kucenas}

A
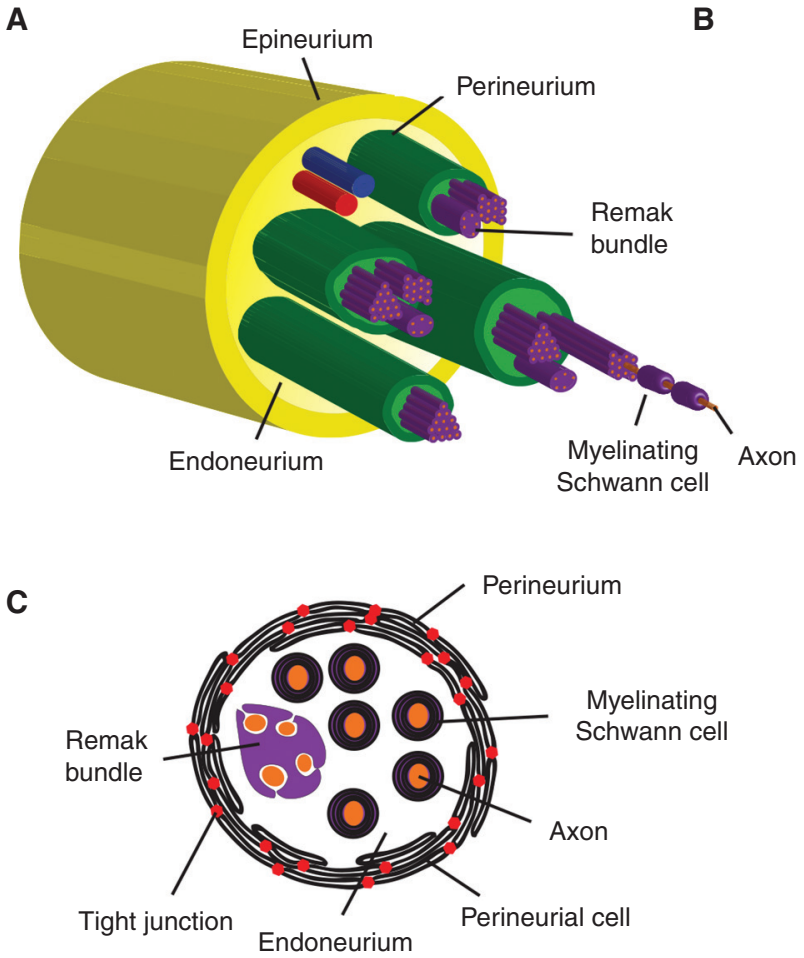
$500 \mathrm{~nm}$. A, axon; M, myelin.

Figure 1. Structure of peripheral nerves. (A) Diagram of the five major cell types that are found in peripheral nerves. Individual axons (orange) are ensheathed by either myelinating or Remak Schwann cells (purple). Multiple axon-Schwann cell complexes reside with the endoneurium (light green), and are ensheathed into fascicles by the perineurium (green). All fascicles within a nerve are then ensheathed in a connective tissue known as the epineurium (dark yellow). (B) Electron micrograph of the edge of a motor nerve showing that perineurial cells have a double basal lamina (black arrowheads) and are connected via tight junctions (red arrowhead). (C) Detailed schematic of an individual nerve fascicle. Multiple axon-Schwann cell complexes are ensheathed in concentric rings of perineurial glia that are connected via tight junctions (red dots). Scale bar,

appa and Bourne 1962, 1963; Burkel 1967; Shantha and Bourne 1968; Haller and Low 1971; Akert et al. 1976). The final nerve element, the epineurium, which is composed of collagen and adipocytes, bundles all of the individual nerve fascicles together into a single nerve structure that is physically separated from surrounding tissue (Fig. 1) (Shantha and Bourne 1968). Although we have an extremely detailed description of the structure of peripheral nerves, very little research has extended past the origin and roles of Schwann cells during nerve development, regeneration, and disease. Using model organisms like zebrafish, which allow for the unique combination of genetic manipulation and in vivo time-lapse imaging, investigations into the glia that compose the perineurium are changing our perspectives on how the PNS is assembled, where PNS cells originate, and the roles of central nervous system (CNS) - derived peripheral glia in not only building a functional peripheral nerve, but also rebuilding it after injury or disease.

In this article, I will provide a detailed review of perineurial glia, the cells that form the mature perineurium. Using studies from zebrafish, Drosophila, chick, and mouse, I will describe their origin, roles in development and regeneration, and potential implication in disease etiology. 


\section{CNS-DERIVED PERINEURIAL GLIA FORM THE MATURE SPINAL MOTOR NERVE PERINEURIUM}

The perineurium, which literally translates to "around the neuron," was first described by Henle in 1841 and named by Key and Retzius in 1876 (Shanthaveerappa and Bourne 1962, 1963; Shantha and Bourne 1968; Akert et al. 1976). The structural descriptions of peripheral nerves performed by these anatomists, as well as Ranvier and others, are still widely accepted today. However, since these first studies almost 200 years ago, we still know very little about the origin of the cells that form the perineurium or their role during development, regeneration, and disease.

Classical descriptive studies using histology and electron microscopy first described the perineurium as a tissue of stratified, squamous epithelial cell layers that were a continuation of the leptomeninges of the spinal cord extending over and covering the entire PNS (Burkel 1967; Shantha and Bourne 1968; Akert et al. 1976). This nerve element can consist of one to many concentric rings of endothelial cells that encase nerve fascicles and eventually individual nerve fibers and terminals (Fig. 1) (Burkel 1967; Shantha and Bourne 1968; Akert et al. 1976). Individual perineurial cells within this structure are extremely thin, have a double basal lamina, and are fitted together by overlapping border zones (Fig. 1) (Burkel 1967; Shantha and Bourne 1968; Akert et al. 1976). Cell contacts at these borders are formed by zonulae occludentes, or tight junctions, and it is these structures that give the perineurium its blood-nerve barrier function (Fig. 1) (Burkel 1967; Shantha and Bourne 1968; Kristensson and Olsson 1971; Akert et al. 1976). Additionally, the cytoplasm of individual perineurial cells is studded with plasmalemmal vesicles, suggesting that this structure has high levels of pinocytotic activity (Burkel 1967; Akert et al. 1976).

Historically, individual perineurial cells were often referred to as fibroblasts because of their shape. Therefore, the origin of the perineurium has traditionally been thought to be the mesoderm (Shantha and Bourne 1968).
However, this conclusion was flawed because perineurial cells and fibroblasts are quite different. A typical fibroblast has a compact nucleus and a large endoplasmic reticulum, whereas perineurial cells do not (Shantha and Bourne 1968). Additionally, perineurial cells have double basement membranes, whereas fibroblasts only have a single basal laminae (Peltonen et al. 1987; Jaakkola et al. 1989). Organizationally, fibroblasts are almost always arranged in a large mass, whereas perineurial cells are joined carefully by tight junctions into a single sheet (Shantha and Bourne 1968). Finally, at nerve terminals, a single perineurial cell can surround a small axon bundle, whereas a fibroblast cannot (Shantha and Bourne 1968). In 1989, a study to determine the cellular origin of the perineurium was performed in vitro by coculturing purified populations of Schwann cells, sensory neurons, and fibroblasts (Bunge et al. 1989). Before culturing, either Schwann cells or fibroblasts were infected with a retrovirus encoding $\beta$-galactosidase. In these studies, "perineurial" cells, or those cells found in the most peripheral location of the nerve-like structures formed in culture, were only lac $\mathrm{Z}^{+}$when fibroblasts were infected with the retrovirus before culturing (Bunge et al. 1989). From these data, the investigators concluded that the perineurium was derived from fibroblasts in vitro and, "by implication, in vivo as well" (Bunge et al. 1989). Although these studies demonstrated that fibroblasts, when cultured with Schwann cells and sensory neurons could ensheath axon-Schwann cell complexes and form an outer casing in culture, they did not form a perineurium (Bunge et al. 1989). Unlike perineurial cells, which express basement membrane-specific genes and form a double basal lamina, the fibroblasts in these studies did neither (Bunge et al. 1989). Therefore, the origin of the cells that form the perineurium is most likely not the mesoderm.

Thus, we are left with two possible origins of this nerve structure. They are (1) the neural crest, and (2) the neuroectoderm. In an elegant study using Wnt1-Cre ${ }^{+}$loxpRosa ${ }^{+}$mice to fate map the contribution of the neural crest to peripheral nerves, endoneurial and Schwann cells were $\mathrm{Wntl}^{+}$and, therefore, neural crest derived 


\section{S. Kucenas}

(Joseph et al. 2004). However, the investigators never found lac $\mathrm{Z}^{+}$perineurial cells, and, thus, concluded that the perineurium did not share the same origin as these other two nerve elements (Joseph et al. 2004).

The last possible origin for perineurial cells is the neuroectoderm. In Drosophila, most peripheral glia, excluding those generated by sensory organ precursors, arise from central neuroblasts (Klambt and Goodman 1991; Schmidt et al. 1997; Sepp et al. 2000, 2001; Freeman and Doherty 2006; Parker and Auld 2006; von Hilchen et al. 2008). Therefore, it is possible that some vertebrate peripheral glia are also CNS derived, and there is significant evidence in the literature to support this hypothesis. Beginning in the early 1900s, anatomists, including Raven, Harrison, Detwiler, and Jones, all performed studies investigating the origin of sheath cells, which we now call Schwann cells (Harrison 1906, 1924; Detwiler 1937; Raven 1937; Lunn et al. 1987). Using chick and frog in combination with vital dye labeling and neural crest removal, all of these investigators concluded that most nerve sheath cells were neural crest derived (Harrison 1906, 1924; Detwiler 1937; Raven 1937; Lunn et al. 1987). However, all of them also noted that, even in the absence of the neural crest, some sheath cells were still present along ventral peripheral nerves and that they must have originated within the neural tube (Harrison 1906, 1924; Detwiler 1937; Raven 1937; Lunn et al. 1987). One possible explanation for the presence of CNS-derived sheath cells in these studies could be the absence of the neural crest. However, Harrison (1924) concludes from his work that the neural crest removal studies do not suggest that neural crest is normally the sole source of sheath cells. Supporting this hypothesis, vital dye labeling of the neural tube during some of these studies demonstrated that some sheath cells, both in the presence and absence of neural crest, are CNS derived (Detwiler 1937). Interestingly, Jones hypothesizes, toward the end of his paper, about the respective contribution of the neural crest versus the neural tube to sensory and motor nerves (Jones 1939; Lunn et al. 1987). He theorizes that the neural crest gives rise to dorsal, or sensory, root sheath cells, whereas the neural tube is the source for ventral, or motor, root sheath cells (Jones 1939; Lunn et al. 1987). This hypothesis is quite interesting and will be discussed again later in this review.

The question of the origin of peripheral nerve Schwann/sheath cells was revisited in 1963 by Weston (1963). Using tritiated thymidine labeling of the neural crest or neural tube, Weston demonstrated that the CNS gave rise to sheath cells that were associated with ventral motor nerves (Weston 1963). However, like the studies performed earlier in the century, the exact identities of the neural tube-derived cells were not determined. Nearly 25 years later, Lunn and colleagues (1987) set out to not only confirm the findings of these previous investigators but also to determine whether the neural tube-derived sheath cells were, in fact, Schwann cells. Previous studies were far from unanimous and some of the techniques used, including vital dye labeling, were not precise, and neighboring cells were often labeled because of diffusion of the dye. Using more modern techniques, including chick-quail chimeras, immunohistochemistry, and electron microscopy, Lunn et al. (1987) identified a small population of cells that appeared to breach the basal lamina of the neural tube exclusively in the region of the ventral motor nerve root. These CNS-derived cells shared some molecular similarities to neural crest-derived Schwann cells, including immunoreactivity to HNK-1 (a marker of neural crest-derived cells), but were not identical (Lunn et al. 1987). Interestingly, these cells were only observed on the ventral motor root, and Lunn and others hypothesized that they may actually aid in motor axon guidance out of the CNS (Nordlander et al. 1981; Lunn et al. 1987). Taken together, all of these studies provide strong evidence for the existence of CNSderived ventral motor root glial cells.

However, this nearly 100 years of study lay, for the most part, dormant in the literature. A few years ago, with the increasing sensitivity of cell-labeling techniques and the possibility of in vivo time-lapse imaging, this argument of whether the ventral nerve cord contributed glial cells to the PNS was revisited in zebrafish. As 
mentioned above, in Drosophila, motor axonensheathing glia are born in the lateral edges of the ventral nerve cord and migrate into the periphery along motor axons in a chain-like fashion (Klambt and Goodman 1991; Schmidt et al. 1997; Sepp et al. 2000, 2001; Parker and Auld 2006). Using transgenic zebrafish, $\operatorname{Tg}(n k x 2.2 a$ : megfp), in which $n k x 2.2 a$ regulatory sequences drive expression of membrane-enhanced green fluorescent protein (EGFP) in lateral floor plate cells, in combination with in vivo time-lapse imaging, we set out to determine whether ven- tral spinal cord cells migrated into the periphery (Fig. 2) (Kucenas et al. 2008). In these studies, we observed that, during stages of motor nerve development $(\sim 40-72 \mathrm{~h}$ postfertilization [hpf ]), $n k x 2.2 a^{+}$cells exited the spinal cord at motor exit points and migrated in chain-like fashion down outgrowing motor axons (Fig. 2) (Kucenas et al. 2008). These $n k x 2.2 a^{+}$cells were always found peripheral to myelin basic protein $(\mathrm{MBP})^{+}$Schwann cells. Using electron microscopy and immunohistochemistry to visualize well-described hallmarks of the perineu-
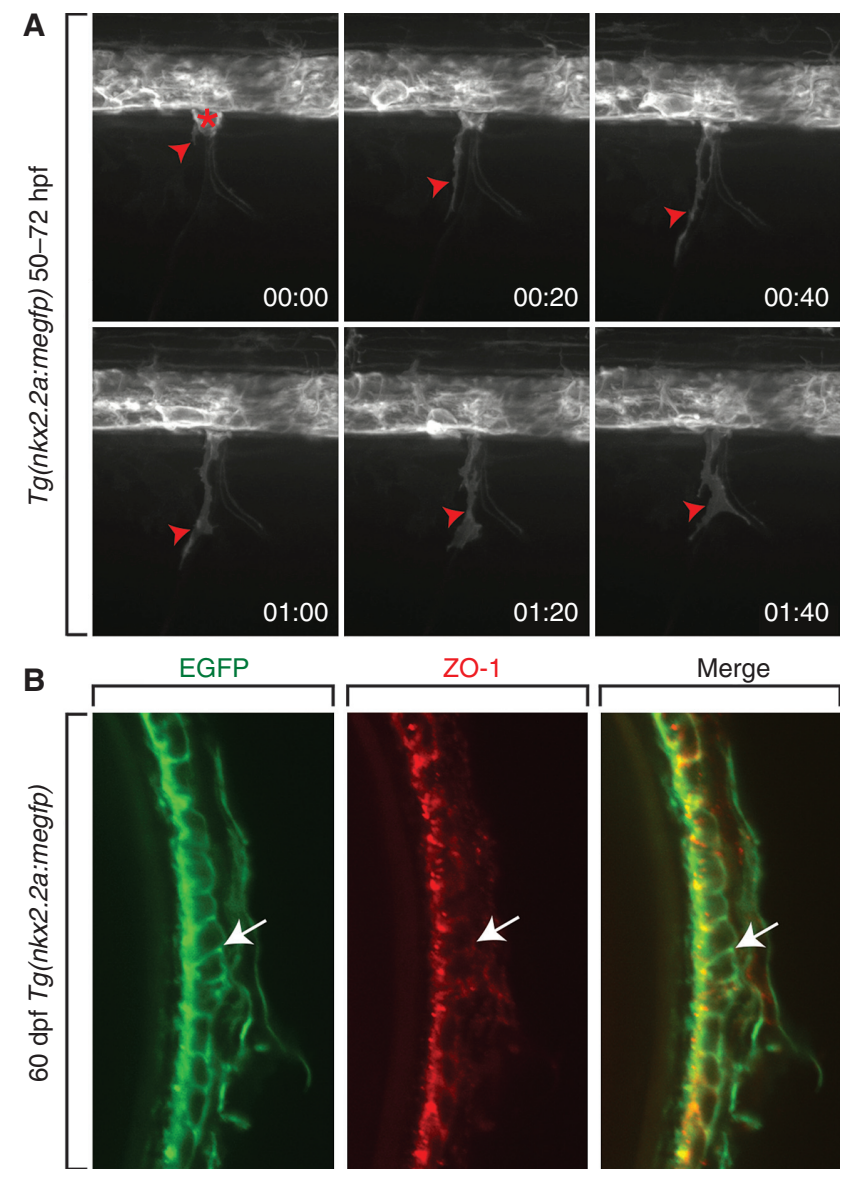

Figure 2. The motor nerve perineurium is composed of CNS-derived perineurial glia. (A) Frames captured from a 22-h time-lapse sequence of a $\operatorname{Tg}(n k x 2.2 a$ :megfp $)$ zebrafish embryo beginning at $50 \mathrm{~h}$ postfertilization (hpf). Numbers in the lower right corners show the time elapsed from the first frame. At $50 \mathrm{hpf}(00: 00)$, a GFP ${ }^{+}$ perineurial process (red arrowhead) exits the CNS and is subsequently followed by a cell body (red asterisk). (B) Transverse section of a 60 -d postfertilization (dpf) $\operatorname{Tg}(n k x 2.2 a$ :megfp) adult. Antibody labeling to ZO-1 shows $\mathrm{GFP}^{+}$perineurial membranes colabeled with this tight junction marker (arrows). 


\section{S. Kucenas}

rium, including tight junctions, we concluded that the motor nerve perineurium was made up of CNS-derived glial cells that ultimately differentiate into the mature motor nerve perineurium that is found in adults (Fig. 2) (Kucenas et al. 2008).

From these findings came two new questions about the origin of the perineurium: (1) Is the perineurium in mammals composed of CNS-derived glial cells? and (2) What is the origin of the sensory nerve perineurium? Recent studies in the laboratory using transgenic mouse reporter lines that label Nkx2.2 $2^{+}$precursors have led us to conclude that at least a subset of perineurial cells in mice also originate within the neural tube as glial cells, demonstrating a conservation of the origin of this essential PNS element (Clark et al. 2014). However, to date, we have been unable to definitely determine the origin of the perineurium that ensheaths sensory nerves. We have ample evidence to demonstrate that it is not composed of CNS-derived $n k \times 2.2 a^{+}$glia (C Smith and S Kucenas, unpubl.). However, this does not rule out the possibility that it is composed of other CNS-derived glia that we have not been able to identify yet because of a lack of molecular markers. What this does highlight is the difference between sensory and motor nerve roots and the asymmetrical contribution of the neural crest and neural tube to each, a hypothesis initially proposed nearly 100 years ago (Jones 1939).

These recent zebrafish and mouse data corroborate previous studies conducted in chick, frog, and Drosophila and directly show, for the first time, the migration of CNS-derived glial cells from the neural tube. In these studies, we conclude that at least a subset of perineurial glia originate within the CNS, although many of the older studies hypothesize that Schwann cells as well as another glial populations are derived from the neural tube (Harrison 1906, 1924; Detwiler 1937; Raven 1937; Lunn et al. 1987). The data from these more recent studies do not rule out the possibility that other peripheral glia, including Schwann cells, also originate from precursors in the CNS, and future studies investigating this possibility with modern techniques promise to yield intriguing results.

\section{PERINEURIAL GLIA DIRECT MOTOR NERVE DEVELOPMENT}

As mentioned above, very few studies have investigated the perineurium as anything other than a barrier structure in adult nervous tissue. However, the in vivo time-lapse imaging showing the early migration of perineurial glia out of the spinal cord during motor nerve development in zebrafish is consistent with the hypothesis that perineurial glia may indeed play an essential role during development.

In both Drosophila and grasshopper, CNSderived peripheral glia have been shown to play vital roles during nerve development (Bastiani and Goodman 1986; Auld 1999; Sepp et al. 2000, 2001). Before motor axons pathfind out of the nerve cord and form the intersegmental nerve, axons interact with a segment boundary cell (SBC), a primitive glial cell that helps establish the location of this nerve (Bastiani and Goodman 1986; Auld 1999). When the SBC is ablated in grasshopper, pioneering primary motor axons fail to turn at the segment boundary and instead continue to migrate within the CNS (Bastiani and Goodman 1986). When a similar experiment is performed in Drosophila and the SBCs, or "exit glia," are genetically removed by overexpressing the cell death genes grim and ced-3, motor axons exit the ventral nerve cord ectopically and this leads to severe motor and sensory nerve pathfinding defects (Sepp et al. 2001). Together, these studies demonstrate that CNS-derived glia prefigure the transition zone (TZ), which is where axons cross between the CNS and PNS and aid in motor axon pathfinding from the CNS (Bastiani and Goodman 1986; Auld 1999; Sepp et al. 2000, 2001).

Because perineurial glia are CNS derived, we hypothesized that they may also play important roles in nerve development, particularly in axon guidance. In zebrafish, when perineurial glial specification was blocked by injecting a morpholino oligonucleotide (MO) to $n k \times 2.2 a$ into single-cell embryos, motor axons exited the CNS ectopically and motor nerves were severely defasciculated (Fig. 3) (Kucenas et al. 2008). Additionally, in embryos lacking perineurial 
Perineurial Glia

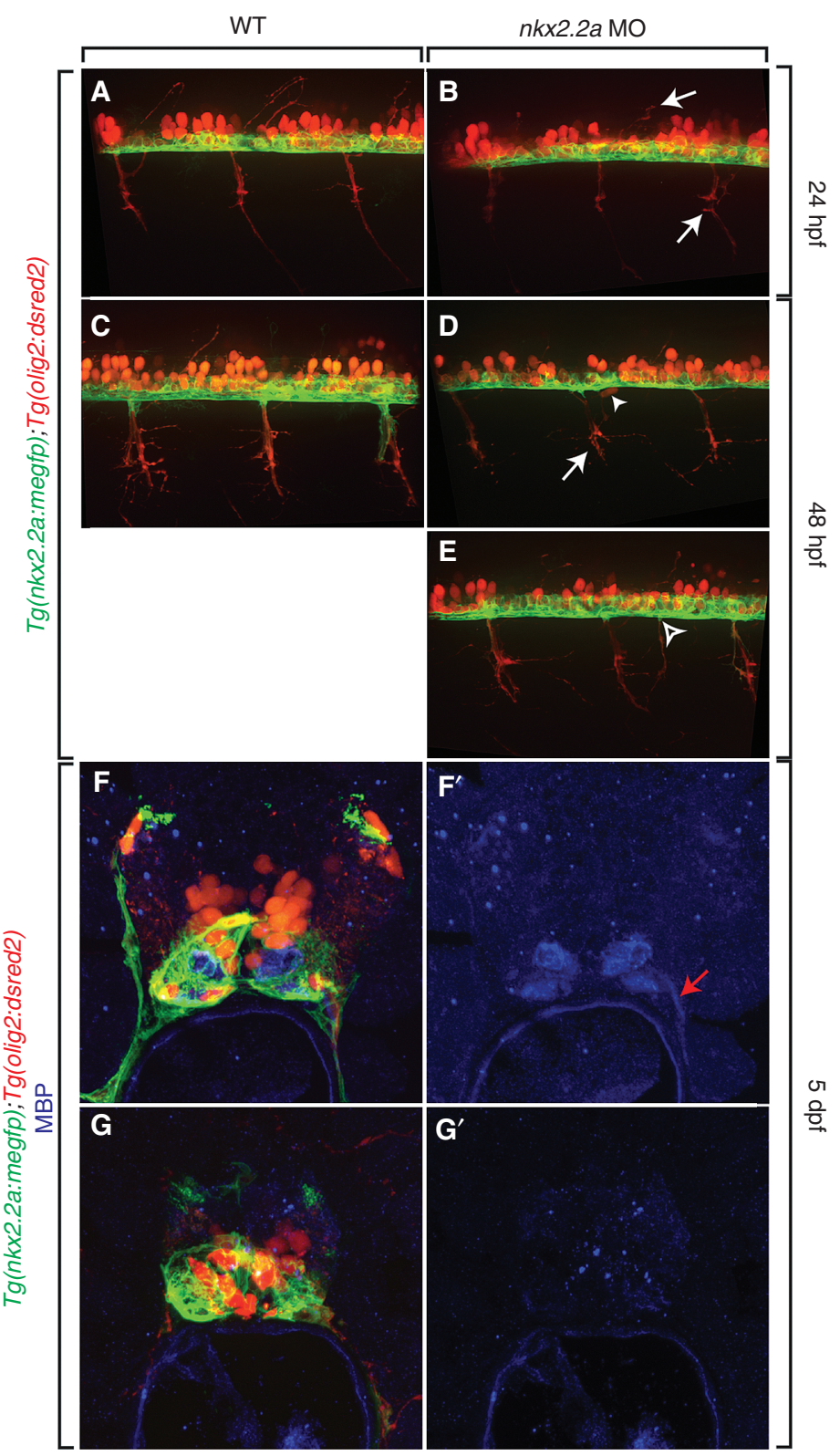

Figure 3. Perineurial glia are required for motor axon pathfinding and Schwann cell differentiation. $(A-E)$ Comparison of motor axon pathfinding in the presence $(A$ and $C)$ and absence $(B, D$, and $E)$ of perineurial glia in $\operatorname{Tg}(n k \times 2.2 a: m e g f p) ; \operatorname{Tg}($ olig2:dsred2) embryos. When perineurial glial specification was blocked by injection of an $n k x 2.2 a \mathrm{MO}$, motor axon development was stalled (arrows) and axons often exited the spinal cord in ectopic locations (open arrowhead). Additionally, motor neuron cells bodies (arrowhead) were observed in the PNS. $\left(F-G^{\prime}\right)$ In these same embryos at $5 \mathrm{dpf}$ labeled with an antibody to MBP, Schwann cells failed to differentiate and myelinate $\left(G\right.$ and $\left.G^{\prime}\right)$ peripheral motor axons as observed in control larvae $\left(F\right.$ and $\left.F^{\prime}\right)$. $A-E$ are lateral views at the level of the trunk spinal cord with dorsal to the top and anterior to the left. $F-G^{\prime}$ are transverse sections of the trunk spinal cord with dorsal to the top. dpf, Days postfertilization; hpf, hours postfertilization; MBP, myelin basic protein; MO, morpholino oligonucleotide; WT, wild type. 


\section{S. Kucenas}

glia, motor neuron cell bodies were observed outside of the spinal cord (Fig. 3) (Kucenas et al. 2008). These data are very similar to that described in insects lacking exit glia and demonstrate an essential role of perineurial glia in motor axon pathfinding and $\mathrm{TZ}$ formation.

In these same studies in zebrafish, we sought to investigate whether motor nerve Schwann cells were also perturbed in the absence of perineurial glia (Kucenas et al. 2008). In embryos injected with $n k x 2.2 a \mathrm{MO}$, sox $10^{+}$Schwann cells showed delayed migration along nascent motor nerves and later failed to form contiguous sheaths of cells around the nerve (Kucenas et al. 2008). Consistent with this, antibody labeling to MBP showed no myelin along motor axons in $n k x 2.2 a$ morphants (Fig. 3) (Kucenas et al. 2008). These data demonstrate that perineurial glia are not only essential for prefiguring the TZ and directing motor axon pathfinding into the periphery, but also for Schwann cell migration and differentiation during development.

\section{REGENERATION}

In addition to their essential roles in motor nerve development, perineurial glia also participate in peripheral regeneration. In the $1920 \mathrm{~s}$ when Ramón y Cajal was studying the nervous system, he described in detail the cellular events he witnessed during peripheral nerve regeneration (Geuna et al. 2009). After the characteristic Wallerian degeneration, which occurs when peripheral axons are severed (Waller 1849), Ramón y Cajal described a reorganization of the distal nerve trunk into many miniature compartments, each surrounded by a new perineurium (Geuna et al. 2009). This phenomenon was later coined "compartmentation" by Morris and occurs initially in the proximal stump after injury and then progresses distally as the nerve regenerates (Morris et al. 1972). These data describing alterations to the perineurium after injury are consistent with the hypothesis that perineurial glia participate in nerve regeneration.

More recently, experiments in rat studying the cellular dynamics of regeneration after sciatic nerve transection described perineurial cells as the first cellular element to bridge the injury gap and this work has since been corroborated by the Llyod laboratory (Schroder et al. 1993; Parrinello et al. 2010). In this recent study, the language "perineurial fibroblasts" is used to describe the cells with a morphology similar to fibroblasts, which accumulate in the injury site. Above, I present preliminary data that supports the hypothesis that the mouse perineurium is not made up of only fibroblasts, but instead of, at least some, CNS-derived perineurial glia (Clark et al. 2014). Therefore, I hypothesize that these fibroblasts the investigators refer to in this study are actually perineurial glia and, thus, demonstrates an important role for these cells following nerve injury.

To more directly investigate the role of perineurial glia after nerve axotomy, we generated a reproducible motor nerve transection assay using laser axotomy in transgenic zebrafish that allows for visualization of perineurial glia before and after injury (Binari et al. 2013; Lewis and Kucenas 2013). When motor nerves were completely transected at $6 \mathrm{dpf}$, a stage when Schwann cells are $\mathrm{MBP}^{+}$and perineurial glia express high levels of tight junctions, we observed an immediate activation of perineurial glia both proximal and distal to the transection (Fig. 4) (Lewis and Kucenas 2013; G Lewis and $S$ Kucenas, unpubl.). Not surprisingly, these perineurial cells extended processes immediately into the injury site, before axonal fragmentation and clearance was complete, and appeared to form a bridge (Fig. 4) (Binari et al. 2013; Lewis and Kucenas 2013; G Lewis and S Kucenas, unpubl.). These data are consistent with previous studies describing the immediate response of perineurial cells to the site of nerve injury and we believe that the perineurial fibroblasts described in previous injury studies are, in fact, perineurial glia.

Interestingly, not only have perineurial cells in rats been described as the initial element that forms a bridge across a nerve injury, they have also been implicated in directing Schwann cell migration across the injury (Parrinello et al. 2010). In this recent study, the investigators elegantly demonstrate that after a nerve injury, the receptor tyrosine kinase Eprhrin B2 (EphB2) is activated on Schwann cells and interacts with 
$\operatorname{Tg}($ nkx2.2a:megfp); $\operatorname{Tg}(o l i g 2: d s r e d 2)$

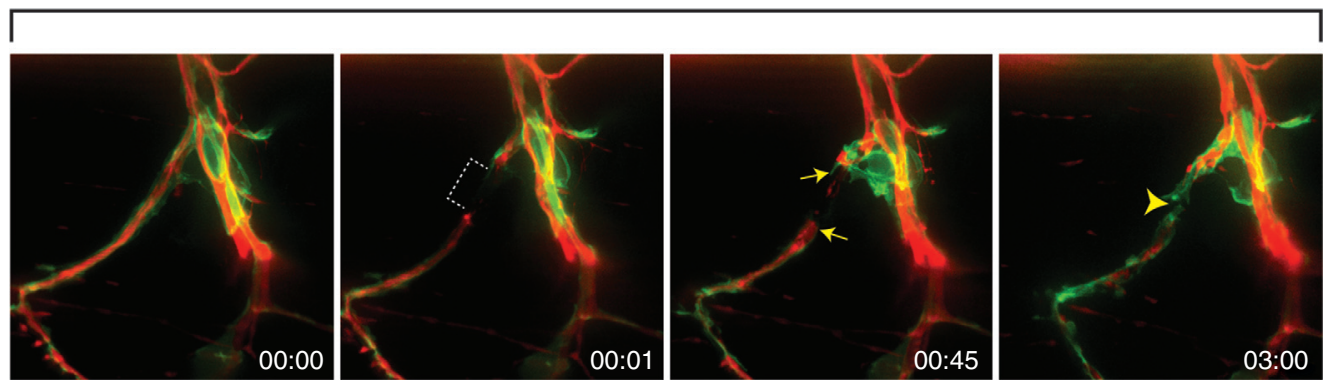

Figure 4. Perineurial glia form bridges after motor nerve axotomy. After laser axotomy of peripheral motor nerves in $6 \mathrm{dpf} \operatorname{Tg}\left(n k x 2.2 a\right.$ :megfp); $\operatorname{Tg}($ olig2: $d s r e d 2)$ larvae, $\mathrm{GFP}^{+}$perineurial glia (arrows) immediately respond to the injury site (dashed bracket) and bridge (arrowhead) the gap. All images are lateral views at the level of the trunk spinal cord with dorsal to the top and anterior to the left.

ephrin-B on perineurial fibroblasts (Parrinello et al. 2010). The investigators show that this receptor-ligand complex allows for the appropriate migration and grouping of Schwann cells along the perineurial bridge and hypothesize that this interaction is essential for nerve regeneration (Parrinello et al. 2010). Consistent with this, when EphB2/ephrin signaling was disrupted in vivo, regenerating axons had aberrant outgrowth (Parrinello et al. 2010).

Taken together, data from rats and zebrafish demonstrate a conserved role of perineurial glia in nerve regeneration by building the bridge that traverses the injury site and directs Schwann cell migration into the distal stump (Schroder et al. 1993; Parrinello et al. 2010; Webber and Zochodne 2010; Lewis and Kucenas 2013). Future studies investigating additional roles of these glia in degeneration and repair, including whether they transdifferentiate and phagocytize debris, which has been demonstrated for neighboring Schwann cells, are sure to yield fascinating results.

\section{RECIPROCAL INTERACTIONS BETWEEN PERINEURIAL GLIA AND SCHWANN CELLS ARE REQUIRED FOR MOTOR NERVE DEVELOPMENT}

Although already briefly discussed throughout this article, the importance of perineurial glialSchwann cell interactions cannot be empha- sized enough. Many recent studies in zebrafish and mouse are demonstrating that there is significant evidence that perineurial glia interact with Schwann cells and are essential for PNS development and health (Mirsky et al. 1999; Parmantier et al. 1999; Sharghi-Namini et al. 2006; Kucenas et al. 2008; Parrinello et al. 2010; Kuspert et al. 2012; Binari et al. 2013; Lewis and Kucenas 2013).

Above, I review data that demonstrate that motor nerve Schwann cell migration and differentiation during development and regeneration is influenced by perineurial glia (Kucenas et al. 2008; Parrinello et al. 2010). A recent study from our laboratory has extended these findings and found that perineurial migration and differentiation also affect Schwann cell differentiation (Binari et al. 2013). In our early studies, we used tools that blocked the specification of perineurial glia, resulting in a nearly complete loss of this glial population (Kucenas et al. 2008). In these studies, severe axon and Schwann cell defects were observed (Kucenas et al. 2008). However, because perineurial glia were absent, we were unable investigate the role of these glia during later stages of development. Using genetic and pharmacological disruption of the Notch signaling cascade, which was previously implicated in the migration of CNS-derived peripheral glia in Drosophila (Edenfeld et al. 2007), we initially inhibited perineurial glial migration from the spinal cord (Binari et al. 


\section{S. Kucenas}

2013). As a result of their failed migration, fewer Schwann cells populated motor nerves and those that did did not differentiate and myelinate peripheral axons (Binari et al. 2013). Interestingly, inhibiting the Notch cascade after perineurial glial migration from the CNS resulted in failed perineurial and Schwann cell differentiation (Binari et al. 2013). These data are consistent with the hypothesis that perineurial glial migration and differentiation are required for subsequent Schwann cell development and differentiation as we found no evidence that Notch activity was cell autonomously required for Schwann cells during these stages (Binari et al. 2013).

The next logical question that stemmed from these studies was whether this interaction between perineurial glia and Schwann cells was reciprocal. Or more simply, Schwann cells need perineurial glia, so do perineurial glia need Schwann cells? Using zebrafish mutants that lack Schwann cells, we demonstrate that the answer is absolutely yes. In colourless ( $c l s$ ) mutant embryos, which harbor a mutation in the transcription factor Sox10, a gene required for the survival of Schwann cells, perineurial glial migration from the spinal cord is severely delayed and they fail to properly ensheath motor axons (Kucenas et al. 2008). In a follow-up study using a double mutant zebrafish line, mont blanc; mother superior (mob;mos), which harbors mutations in the transcription factors Tfap $2 \mathrm{a}$ and Foxd3, neural crest induction fails and Schwann cells are absent from all peripheral nerves (Kucenas et al. 2009). In these mutant embryos, perineurial glia completely fail to exit the neural tube (Kucenas et al. 2009). Surprisingly, however, we instead observed oligodendrocyte progenitor cells (OPC) migrate out of the spinal cord via the motor exit point (MEP) and myelinate peripheral motor axons (Kucenas et al. 2009). These data demonstrate that perineurial glial development is intimately coordinated with the development of Schwann cells and that reciprocal interactions between these two glial populations is essential for motor nerve assembly. These data also reveal that in the absence of all peripheral glia, OPCs exit the CNS. To determine which peripheral glial population,
Schwann cells or perineurial glia, are responsible for OPC migration from the spinal cord, we investigated mutants in which peripheral glial development is perturbed, but perineurial glia still exit the spinal cord. One example of this phenotype is the erbb3b mutant, which harbors a mutation in the receptor tyrosine kinase erbb3b, which, in turn, is required for Schwann cell association with axons (Lyons et al. 2005). In these mutant embryos, perineurial glia exit the spinal cord normally even in the absence of Schwann cells (A Morris and S Kucenas, unpubl.). However, interestingly, OPCs still ectopically exit the CNS, demonstrating that perineurial glia do not restrict their migration (A Morris and S Kucenas, unpubl.). Therefore, we hypothesize that Schwann cells or some other similar peripheral glial population lost in these mutants must be responsible for this repulsion. This raises the intriguing possibility that not only do glia interact in the PNS, but also across the MEP.

The requirement of Schwann cells for perineurial development has also been documented in mouse. In a series of studies published by the Jessen and Mirsky laboratories, the investigators describe the requirement of Schwann cell-derived Desert Hedgehog (DHh), a morphogen, for perineurial development and differentiation (Mirsky et al. 1999; Parmantier et al. 1999; Sharghi-Namini et al. 2006). In the absence of Schwann cell-derived DHh, the perineurium is thin and disorganized, has a patchy basal lamina, and fails to express tight junction proteins (Mirsky et al. 1999; Parmantier et al. 1999). Interestingly, in the mice lacking DHh, perineurial cells invade into the endoneurium and form minifascicles, similar to those that were described in regenerating nerves (Mirsky et al. 1999). From their studies, the investigators hypothesize that DHh secreted by Schwann cells acts directly on the surrounding perineurium to morphologically and functionally differentiate this nerve element (Mirsky et al. 1999). Recently, these findings were corroborated in a study investigating the link between mutations in Sox10 and nerve defects that were not restricted to just Schwann cells (Kuspert et al. 2012). In this study, the investigators demon- 
strate that Sox10 normally activates DHh expression in Schwann cells via an enhancer that is located within the first intron of the Dhh gene (Kuspert et al. 2012). In Sox10 mutants, perineurial phenotypes very similar to those see in Dhh mutants were observed, and the investiga- tors conclude that this is likely caused by the lack of Dhh expression in these animals (Kuspert et al. 2012).

Taken together, these studies shed light on the complex and essential interactions that occur between Schwann cells and perineurial glia
A
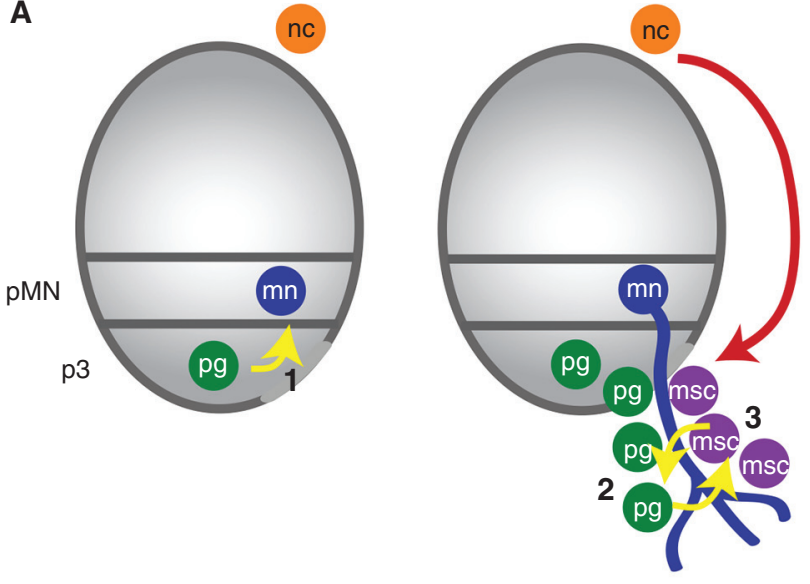

B

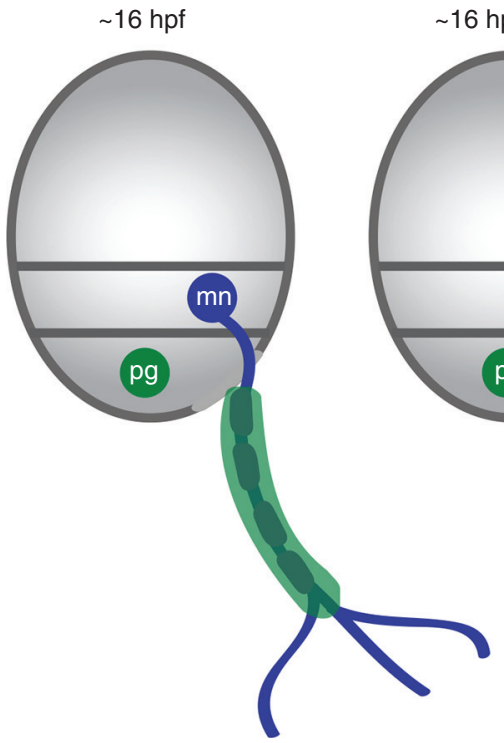

16 hpf-60 hpf

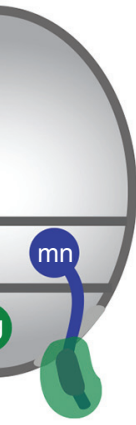

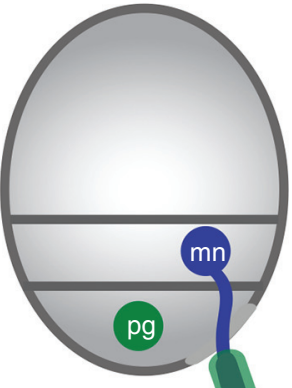

4

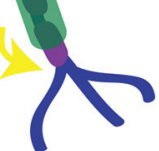

$60 \mathrm{hpf}-96 \mathrm{hpf}$
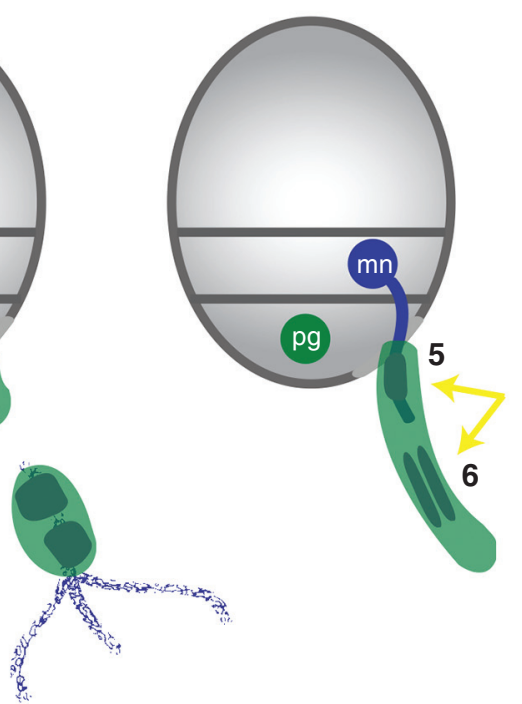

Figure 5. Roles of perineurial glia during motor nerve development and regeneration. $(A)$ During development, CNS-derived perineurial glia play essential roles in (1) guiding motor axons through the motor exit point (MEP), and (2) directing Schwann cell migration along axons. (3) Reciprocal interactions with Schwann cells also direct perineurial migration from the CNS. (4) Additionally, perineurial glial migration and differentiation also influence Schwann cell differentiation. (B) During regeneration, perineurial glia (5) are the first nerve element to bridge the injury site and (6) direct Schwann cells to form cords to allow for axonal regeneration into the target tissue. Gray ovals are transverse views through the spinal cord with dorsal to the top. Yellow arrows denote perineurial glial interactions along the motor nerve. hpf, Hours postfertilization; mn, motor neuron; msc, motor Schwann cell; nc, neural crest; pg, perineurial glia; pMN, premotor neuron domain. 


\section{S. Kucenas}

during development and regeneration. Understanding whether these reciprocal perineurial glial-Schwann interactions are sustained for the life of an organism and identifying the molecular mechanisms that mediate these events may shed light on diseases of the PNS, particularly those of unknown cause.

\section{CONCLUSIONS}

In this article, I have reviewed the origin of perineurial glia and their functional roles during nervous system development and regeneration (Fig. 5). I have also described what we know about their interactions with neighboring glial populations, including Schwann cells (Fig. 5). In the last 15 years, we have learned so much about this previously ignored glial population, and some of these findings, including the revelation that peripheral glia can originate within the CNS, are changing the way we view nervous system development and disease. Therefore, not surprisingly, new research questions concerning peripheral glia and their roles in development, maintenance, and regeneration of the nervous system are emerging. A few of these include:

1. Are there subpopulations of perineurial glia? The $n k \times 2.2 a^{+}$perineurial glia identified in zebrafish only ensheath motor axons (Kucenas et al. 2008). Where do sensory perineurial glia originate and do they play similar roles during development and regeneration of these nerves?

2. If perineurial glia are CNS derived in Drosophila, zebrafish, and mouse (Sepp et al. 2001; Kucenas et al. 2008; Clark et al. 2014), could there be other peripheral glia that also originate in the neural tube? A recent study investigating remyelination dynamics in a mouse model of demyelination demonstrated that Olig $2^{+}$precursors in the spinal cord are capable of producing Schwann cells under demyelinating conditions (Zawadzka et al. 2010). Does this mean that a subpopulation of Schwann cells are CNS derived?

3. Do perineurial glia trans-differentiate after injury like neighboring Schwann cells? Initial studies investigating the role of perineurial glia in regeneration demonstrate an important role in bridging the injury site (Schroder et al. 1993; Parrinello et al. 2010; Lewis and Kucenas 2013; G Lewis and S Kucenas, unpubl.). However, we do not know whether these cells play additional roles during axon fragmentation and clearance.

4. Do perineurial glia play important roles during nerve maintenance and could they be the underlying cause of some peripheral neuropathies?

The perineurium is a component of the blood-nerve barrier and is composed, at least in part, of CNS-derived perineurial glia that play essential roles during nervous system development and regeneration. Although ignored for more than 100 years after their first description, a surge in research is now uncovering intriguing details about this glial population that changes our way of thinking about nervous system development and disease. A better understanding of the role of perineurial glia in neural development will shed light not only the basic mechanisms needed to build a nervous system, but also those needed to rebuild a nervous system.

\section{ACKNOWLEDGMENTS}

I thank Angela Morris, Gwendolyn Lewis, and Cody Smith for the use of their unpublished data for this article and Bruce Appel, my postdoctoral mentor, for allowing me to follow these glia wherever they took me.

\section{REFERENCES}

Akert K, Sandri C, Weibel ER, Peper K, Moor H. 1976. The fine structure of the perineural endothelium. Cell Tissue Res 165: 281-295.

Auld VJ. 1999. Glia as mediators of growth cone guidance: Studies from insect nervous systems. Cell Mol Life Sci 55: 1377- 1385 .

Bastiani MJ, Goodman CS. 1986. Guidance of neuronal growth cones in the grasshopper embryo: III. Recognition of specific glial pathways. J Neurosci 6: 3542-3551.

Binari LA, Lewis GM, Kucenas S. 2013. Perineurial glia require notch signaling during motor nerve de- 
velopment but not regeneration. J Neurosci 33: 42414252.

Bunge MB, Wood PM, Tynan LB, Bates ML, Sanes JR. 1989. Perineurium originates from fibroblasts: Demonstration in vitro with a retroviral marker. Science 243: 229-231.

Burkel WE. 1967. The histological fine structure of perineurium. Anat Rec 158: 177-189.

Clark JK, O'Keefe A, Mastracci TL, Sussel L, Matise MP, Kucenas S. 2014. Mammalian Nkx2.2 $2^{+}$perineurial glia are essential for motor nerve development. Dev Dyn 243: 1116-1129.

Cravioto H. 1965. Studies on the normal ultrastructure of peripheral nerve: Axis cylinders, Schwann cells and myelin. Bull Los Angeles Neurol Soc 30: 169-190.

Detwiler SR. 1937. Application of vital dyes to the study of sheath cell origin. Proc Soc Exp Biol Med 37: 380-382.

Edenfeld G, Altenhein B, Zierau A, Cleppien D, Krukkert K, Technau G, Klämbt C. 2007. Notch and Numb are required for normal migration of peripheral glia in Drosophila. Dev Biol 301: 27-37.

Freeman MR, Doherty J. 2006. Glial cell biology in Drosophila and vertebrates. Trends Neurosci 29: 82-90.

Gamble HJ, Eames RA. 1964. An electron microscope study of the connective tissues of human peripheral nerve. $J$ Anat 98: 655-663.

Geuna S, Raimondo S, Ronchi G, Di Scipio F, Tos P, Czaja K, Fornaro M. 2009. Chapter 3: Histology of the peripheral nerve and changes occurring during nerve regeneration. Int Rev Neurobiol 87: 27-46.

Haller FR, Low FN. 1971. The fine structure of the peripheral nerve root sheath in the subarachnoid space in the rat and other laboratory animals. Am J Anat 131: 1-19.

Harrison RG. 1906. Further experiments on the development of peripheral nerves. Am J Anat 5: 121-131.

Harrison RG. 1924. Neuroblast versus sheath cell in the development of peripheral nerves. J Comp Neurol 37: 123-194.

Jaakkola S, Peltonen J, Uitto JJ. 1989. Perineurial cells coexpress genes encoding interstitial collagens and basement membrane zone components. J Cell Biol 108: 1157-1163.

Jessen KR, Mirsky R. 2005. The origin and development of glial cells in peripheral nerves. Nat Rev Neurosci 6: 671682.

Jones DS. 1939. Studies on the origin of sheath cells and sympathetic ganglia in the chick. Anat Rec 73: 343-357.

Joseph NM, Mukouyama YS, Mosher JT, Jaegle M, Crone SA, Dormand EL, Lee KF, Meijer D, Anderson DJ, Morrison SJ. 2004. Neural crest stem cells undergo multilineage differentiation in developing peripheral nerves to generate endoneurial fibroblasts in addition to Schwann cells. Development 131: 5599-5612.

Klambt C, Goodman CS. 1991. The diversity and pattern of glia during axon pathway formation in the Drosophila embryo. Glia 4: 205-213.

Kristensson K, Olsson Y. 1971. The perineurium as a diffusion barrier to protein tracers. Differences between mature and immature animals. Acta Neuropathol 17: 127138.

Kucenas S, Takada N, Park H-C, Woodruff E, Broadie K, Appel B. 2008. CNS-derived glia ensheath peripheral nerves and mediate motor root development. Nat Neurosci 11: 143-151.

Kucenas S, Wang W-D, Knapik EW, Appel B. 2009. A selective glial barrier at motor axon exit points prevents oligodendrocyte migration from the spinal cord. J Neurosci 29: 15187-15194.

Kuczynski K. 1980. Histology of the peripheral nerve trunks. Int Surg 65: 495-498.

Kuspert M, Weider M, Muller J, Hermans-Borgmeyer I, Meijer D, Wegner M. 2012. Desert Hedgehog links transcription factor Sox 10 to perineurial development. J Neurosci 32: 5472-5480.

Lewis GM, Kucenas S. 2013. Motor nerve transection and time-lapse imaging of glial cell behaviors in live zebrafish. $J$ Vis Exp 20: e50621.

Lunn ER, Scourfield J, Keynes RJ, Stern D. 1987. The neural tube origin of ventral root sheath cells in the chick embryo. Development 247-254.

Lyons DA, Pogoda HM, Voas MG, Woods IG, Diamond B, Nix R, Arana N, Jacobs J, Talbot WS. 2005. erbb3 and erbb2 are essential for Schwann cell migration and myelination in zebrafish. Curr Biol 15: 513-524.

Mirsky R, Jessen KR. 1999. The neurobiology of Schwann cells. Brain Pathol 9: 293-311.

Mirsky R, Parmantier E, McMahon AP, Jessen KR. 1999. Schwann cell-derived Desert Hedgehog signals nerve sheath formation. Ann NY Acad Sci 883: 196-202.

Morris JH, Hudson AR, Weddell G. 1972. A study of degeneration and regeneration in the divided rat sciatic nerve based on electron microscopy: II. The development of the "regenerating unit." Z Zellforsch Mikrosk Anat 124: 103.

Nordlander RH, Singer JF, Beck R, Singer M. 1981. An ultrastructural examination of early ventral root formation in amphibia. J Comp Neurol 199: 535-551.

Parker RJ, Auld VJ. 2006. Roles of glia in the Drosophila nervous system. Semin Cell Dev Biol 17: 66-77.

Parmantier E, Lynn B, Lawson D, Turmaine M, Namini SS, Chakrabarti L, McMahon AP, Jessen KR, Mirsky R. 1999. Schwann cell-derived Desert Hedgehog controls the development of peripheral nerve sheaths. Neuron 23: $713-$ 724.

Parrinello S, Napoli I, Ribeiro S, Digby PW, Fedorova M, Parkinson DB, Doddrell RD, Nakayama M, Adams RH, Lloyd AC. 2010. EphB signaling directs peripheral nerve regeneration through Sox2-dependent Schwann cell sorting. Cell 143: 145-155.

Peltonen J, Jaakkola S, Virtanen I, Pelliniemi L. 1987. Perineurial cells in culture. An immunocytochemical and electron microscopic study. Lab Invest 57: 480-488.

Raven CP. 1937. Experiments on the origin of the sheath cells and the sympathetic neuroblasts in amphibia. J Comp Neurol 67: 221-280.

Schmidt H, Rickert C, Bossing T, Vef O, Urban J, Technau GM. 1997. The embryonic central nervous system lineages of Drosophila melanogaster: II. Neuroblast lineages derived from the dorsal part of the neuroectoderm. Dev Biol 189: 186-204.

Schroder JM, May R, Weis J. 1993. Perineurial cells are the first to traverse gaps of peripheral nerves in silicone tubes. Clin Neurol Neurosurg 95: S78-83. 


\section{S. Kucenas}

Sepp KJ, Schulte J, Auld VJ. 2000. Developmental dynamics of peripheral glia in Drosophila melanogaster. Glia 30: $122-133$.

Sepp KJ, Schulte J, Auld VJ. 2001. Peripheral glia direct axon guidance across the CNS/PNS transition zone. Dev Biol 238: $47-63$.

Shantha TR, Bourne GH. 1968. The perineural epithelium-A new concept. In The Structure and function of nervous tissue, Vol. 1, p. 379. Academic, New York.

Shanthaveerappa TR, Bourne GH. 1962. A perineural epithelium. J Cell Biol 14: 343-346.

Shanthaveerappa TR, Bourne GH. 1963. The perineural epithelium: Nature and significance. Nature 199: 577-579.

Sharghi-Namini S, Turmaine M, Meier C, Sahni V, Umehara F, Jessen KR, Mirsky R. 2006. The structural and functional integrity of peripheral nerves depends on the glial-derived signal desert hedgehog. J Neurosci 26: 6364-6376.

von Hilchen CM, Beckervordersandforth RM, Rickert C, Technau GM, Altenhein B. 2008. Identity, origin, and migration of peripheral glial cells in the Drosophila embryo. 125: 337-352.

Waller A. 1849. Experiments on the section of the glossopharyngeal and hypoglossal nerves of the frog, and observations of the alterations produced thereby in the structure of their primitive fibres. Phil Trans $R$ Soc Lond 423-429.

Webber C, Zochodne D. 2010. The nerve regenerative microenvironment: Early behavior and partnership of axons and Schwann cells. Exp Neurol 223: 51-59.

Weston JA. 1963. A radioautographic analysis of the migration and localization of trunk neural crest cells in the chick. Dev Biol 6: 279-310.

Zawadzka M, Rivers LE, Fancy SPJ, Zhao C, Tripathi R, Jamen F, Young K, Goncharevich A, Pohl H, Rizzi M, et al. 2010. CNS-resident glial progenitor/stem cells produce Schwann cells as well as oligodendrocytes during repair of CNS demyelination. Cell Stem Cell 6: 578590. 


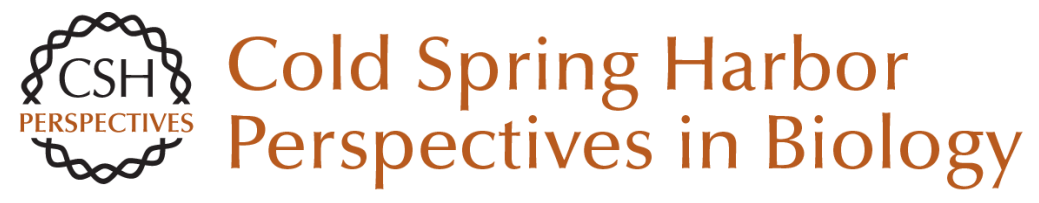

\section{Perineurial Glia}

\section{Sarah Kucenas}

Cold Spring Harb Perspect Biol 2015; doi: 10.1101/cshperspect.a020511 originally published online March 27, 2015

\section{Subject Collection Glia}

The Nodes of Ranvier: Molecular Assembly and Maintenance

Matthew N. Rasband and Elior Peles

Microglia in Health and Disease

Richard M. Ransohoff and Joseph El Khoury

The Astrocyte: Powerhouse and Recycling Center Bruno Weber and L. Felipe Barros

Microglia Function in Central Nervous System

Development and Plasticity

Dorothy P. Schafer and Beth Stevens

Transcriptional and Epigenetic Regulation of Oligodendrocyte Development and Myelination in the Central Nervous System

Ben Emery and Q. Richard Lu

Origin of Microglia: Current Concepts and Past

Controversies

Florent Ginhoux and Marco Prinz

Glia Disease and Repair--Remyelination

Robin J.M. Franklin and Steven A. Goldman

\section{Astrocytes in Neurodegenerative Disease}

Hemali Phatnani and Tom Maniatis
Oligodendrocyte Development and Plasticity Dwight E. Bergles and William D. Richardson

Oligodendrocytes: Myelination and Axonal

Support Mikael Simons and Klaus-Armin Nave

Drosophila Central Nervous System Glia Marc R. Freeman

Perisynaptic Schwann Cells at the Neuromuscular

Synapse: Adaptable, Multitasking Glial Cells Chien-Ping Ko and Richard Robitaille

Astrocytes Control Synapse Formation, Function, and Elimination Won-Suk Chung, Nicola J. Allen and Cagla Eroglu

Schwann Cell Myelination James L. Salzer

Schwann Cells: Development and Role in Nerve Repair

Kristján R. Jessen, Rhona Mirsky and Alison C. Lloyd

Perineurial Glia

Sarah Kucenas

For additional articles in this collection, see http://cshperspectives.cshlp.org/cgi/collection/

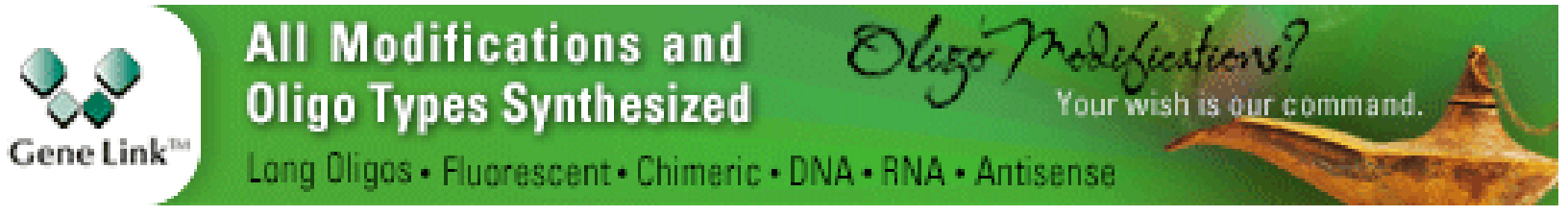

